\title{
Oculo-visual status of the welders in the Capricorn District of the Limpopo Province of South Africa*
}

\author{
HL Sithole**, OA Oduntan+ and MO Oriowo ${ }^{\#}$
}

** University of South Africa, Academic and Research Portfolio, Research Directorate, PO Box 392, UNISA, 0003 South Africa

+ University of KwaZulu-Natal, Faculty of Health Sciences, Discipline of Optometry, Private Bag X 54001, Durban, 4000 South Africa

\# King Saud University, College of Applied Medical Sciences, Department of Optometry, PO Box 10219, Riyadh, 11433 Saudi Arabia

$* *<$ sithoh1@unisa.ac.za>
$+<$ oduntanoa@ukzn.ac.za>
\#<matoriowo@yahoo.com>

Received 4 October 2008; revised version accepted 30 January 2009

\begin{abstract}
The process of welding can lead to several ocular disorders when adequate protective precautions are not taken. There is a possibility that welders in the Limpopo Province of South Africa are not taking adequate precautions due to lack of knowledge on the adverse effects of welding. Good vision is also important for effective and injury-free welding. This study therefore screened welders in the Capricorn district of the Limpopo Province for oculo-visual disorders. Case history established visual symptoms among the welders and ophthalmic tests such as visual acuity (VA) measurement, pinhole, ophthalmoscopy, external assessment of the adnexa and Amsler grid were used to determine their oculo-visual status. One hundred and fifty welders were included in the study and their ages ranged from 18 to 65 years with a mean of $39 \pm$ 14.9 years. Reduced distance vision was reported
\end{abstract}

by $32 \%$ of the welders, $14 \%$ reported reduced vision at near; $43 \%$ reported double vision and $11 \%$ reported colour vision anomaly. Forty seven percent of the welders had VA less than $6 / 6$ at distance and $8 \%$ could only read $1 \mathrm{M}$ or larger print at near. Following the pinhole test, there was no improvement in $7 \%$ of the welders who had VA less than $6 / 6$, indicating a possibility of pathological conditions. Amsler grid showed that $6 \%$ of the welders had possible macular disorders. Ophthalmoscopy and external observations revealed that $7 \%$ of the welders had cup disc ratio $(\mathrm{H} / \mathrm{V})$ of more than $0.6 / 0.5$, Fourteen percentage $(14 \%)$ had pterygia and $5 \%$ had pinguecula. The study established that, although many of the welders had normal oculovisual status, there were a few with ocular disorders which warrant further assessment and management by eye care professionals.

Key words: Oculo-visual conditions, welding, welders, Limpopo Province

**BOptom MOptom

$+\mathrm{BSc}$ (Hons)Optom PhD

\#BSc (Hons)Optom MSc PhD

* This paper forms part of research for the degree Master in Optometry (MOptom) at the University of Limpopo undertaken by HL Sithole under the supervision of Professors OA Oduntan and MO Oriowo. 


\section{Introduction}

Welding is a process of joining two or more similar pieces of metal into one continuous body ${ }^{1}$. In the twenty-first century, it is still a common and a highly skilled occupation ${ }^{2}$. There are nearly 60 different welding processes which are currently in use. However, there are two major types: shielded metal arc and gas (oxyacetylene) welding ${ }^{3}$, both of which are associated with adverse health effects from chemical and physical agents ${ }^{4}$.

Common chemical and physical hazards include fumes, gases and ultraviolet radiation (UVR) respectively ${ }^{4}$, all of which are associated with adverse effects on the eye. Although fumes and gases can cause eye irritation when welding is done in confined spaces, UVR emitted by the electric arc is the most harmful to the eye $\mathrm{e}^{4}$. Therefore, the process of welding is potentially hazardous to the eye if adequate eye protective devices are not worn. Substantial evidence exists to implicate UVR as the primary, or at least a contributing cause to a number of ocular conditions. Repeated exposure to natural UVR sources such as sunlight, as well as other noxious stimuli is thought to be associated with slowly degenerative changes of the conjunctival epithelium such as pterygium and pingueculae ${ }^{5}$ and have been seen in some welders ${ }^{6}$. Other conditions such as squamous cell carcinoma $(\mathrm{SCC})^{7}$, basal cell carcinoma $(\mathrm{BCC})^{8}$, malignant melanoma ${ }^{9}$, cataract $^{10}$ and possibly age related macular degeneration ${ }^{11}$ have also been reported to affect welders.

The absorption of UVR by the various components of the eye depends upon their wavelengths ${ }^{12}$. Retinal effects relating to UVR, for example, can only result from UVA radiation, since the shorter wavelength UVC and UVB radiation are absorbed by other components such as the cornea, aqueous humour and the lens of the eye ${ }^{13}$. Also, the macular is susceptible to the harmful effects of UVA which may result in agerelated macular degeneration ${ }^{11}$.

In an epidemiologic study, Holly et al. ${ }^{14}$, reported that increased risk of intraocular melanomas is associated with high exposure to UVB. High exposure to UVB can also cause cancer of the uveal tract ${ }^{15}$ and photokeratitis ${ }^{16}$ which is the ocular effect most directly attributable to environmental exposures to UVR. Also, high exposure to UVC may cause basal cell carcinoma, squamous cell carcinoma and malignant melanoma ${ }^{17}$. These ocular disorders suggest the need for adequate eye protection whenever welding operations are being carried out.

Though welders are generally shielded from harmful radiation and mechanical injuries by protective means such as safety goggles and helmets ${ }^{18}$, radiation may enter the welding helmet from behind and be reflected into the welder's eyes by the filter glass ${ }^{19}$. When not protected, welders may be exposed to their own welding arc or the arc of nearby welders. Also, they are usually in the vicinity of nearby welding activity and this often exposes them to radiation from their peripheral visual fields ${ }^{20}$. These inadvertent exposures may also cause ocular injuries ${ }^{21}$.

The South African Occupational Health and Safety $\mathrm{Act}^{22}$ requires that during welding, flame cutting, soldering and similar operations no employer or user shall require or permit welding operations to be undertaken, unless i) the person operating the equipment has been fully instructed in the safe operation and use of such equipment and in the hazards which may arise from its use, ii) effective protection is provided and used for the eyes and where necessary, for the face and body of persons performing such operations, as well as against heat, incandescent or flying particles and dangerous radiation, and iii) the workplace is effectively partitioned off where practicable and where not practicable, all the other persons exposed to the hazards are warned and provided with suitable protective equipment. However, a shortcoming of the Act is that the types of devices for specific welding process are not explicitly indicated. The most appropriate protective devices such as safety goggles should always be used during most industrial activities including welding. This is because they fit the face immediately surrounding the eyes and form a protective seal around the eyes. This prevents objects from entering under or around the goggles ${ }^{23}$. The use of ineffective devices may result in eye injuries, therefore it is as dangerous as not wearing any device.

In view of the various oculo-visual and systemic health hazards associated with welding, and the absence of previous eye-related studies among welders in South Africa, this project was carried out to study the oculo-visual conditions of welders in the Capricorn District of the Limpopo Province of South Africa. 


\section{Methods}

A map of the Capricorn District of the Limpopo Province was obtained from the Geography Department of the University of Limpopo and all the five municipalities were chosen for study. The capital of each municipality was included in the study. All the towns and villages shown on the map of each municipality were numbered and a person who did not know what the numbers represented was asked to select four of the numbers. Therefore, a total of 25 towns and villages were the study sites for this project. The proposal for this study was approved by the University of Limpopo Research and Ethics Committee. Welding workshops and industries were sought in each of the 25 study sites and all the 25 study sites were included in the study. Permission was obtained from the managers of the industries or workshops and individual welders before the commencement of the study. All welders in each workshop found were included in the study except those younger than 18 years. According to the Constitution of the Republic of South Africa ${ }^{24}$, child labour is not allowed and this refers to individuals younger than 18 years who were excluded in this study.

The University of Limpopo research consent form was given to each welder for completion and those who needed assistance were assisted by the researcher or a research assistant. Welders were told that participation in the study was voluntary and that they were free to withdraw from participation at any stage. All those requested to participate in the study completed the form, therefore, nobody was excluded from the study as a result of refusal to complete the consent form.

Case history was used to establish visual symptoms among the welders. Ophthalmic tests such as visual acuity (VA) measurement, pinhole, ophthalmoscopy, external assessment and Amsler grid were used to assess their oculo-visual status. Descriptive statistics were used to analyze results using the Statistical Packages for Social Sciences (SPSS) and Microsoft Excel statistical packages.

\section{Results}

The total number of welders included in the study was 150 and they were all males and were black South
Africans. The majority, 64\% (96), of the welders were found in the towns and cities and the other $36 \%$ (54) were found in the villages. Their ages ranged from 18 to 65 years with a mean of $39 \pm 14.9$ years. The most common age group, which was 20 to 30 years accounted for $61 \%$ (92) of the 150 participants. Only a few welders, $12 \%$ (18), were 50 years or older. In the case history, all welders reported having one or more visual problems. The various visual problems and their distribution are shown in Figure 1.

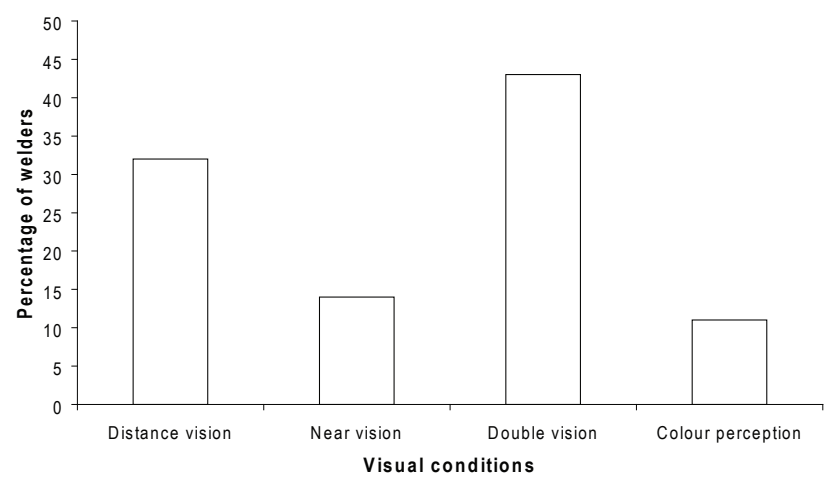

Figure 1: Reported visual conditions and percentages of the respondents.

Among the 32\% (48) of the welders who reported poor distance vision, 58\% (28) reported that they had recently experienced this problem. Among the 14\% (21) who reported near vision problems, $43 \%$ (9) indicated that the problems have existed for a long time. Among the 43\% (65) welders who reported experiencing occasional double vision, $37 \%$ (24) experienced the problems recently. The reported frequency of colour vision problem experiences by $11 \%$ (16) of the welders is shown in Figure 2.

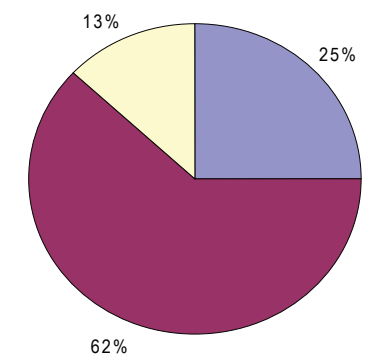

$\square$ Previous 1 month
Previous 3 months $\square$ Previous 3 months
$\square$ More than 12 months

Figure 2: Reported frequency of colour vision problem experiences and percentages of the respondents. A few welders (13\%) reported having had this problem for longer than 12 months. 
A few of the welders, $15 \%$ (22), reported that they have previously sustained eye injuries during welding and the other $85 \%$ (128) reported they have never had any eye injuries. The types of injuries sustained were not established. The reported frequency of eye injuries sustained is shown in Figure 3.

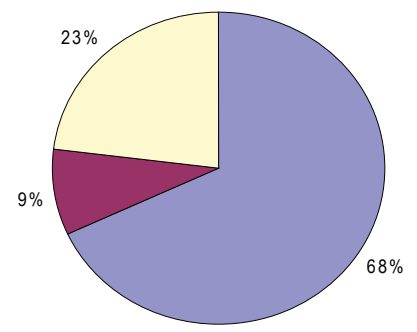

$\square$ Previous 1 month

$\square$ Previous 3 months

$\square$ More than 12 months

Figure 3: Reported frequency of injuries sustained and the percentages of the respondents. The majority $(68 \%)$ of the welders sustained eye injuries in the previous one month.

Unaided distance VA of $6 / 6$ or better was found in $53 \%(80)$ of the welders. The other welders, $47 \%$ (70), however, had unaided VA between $6 / 7.5$ and $6 / 18$. The near binocular unaided reading acuities are as shown in Figure 4.

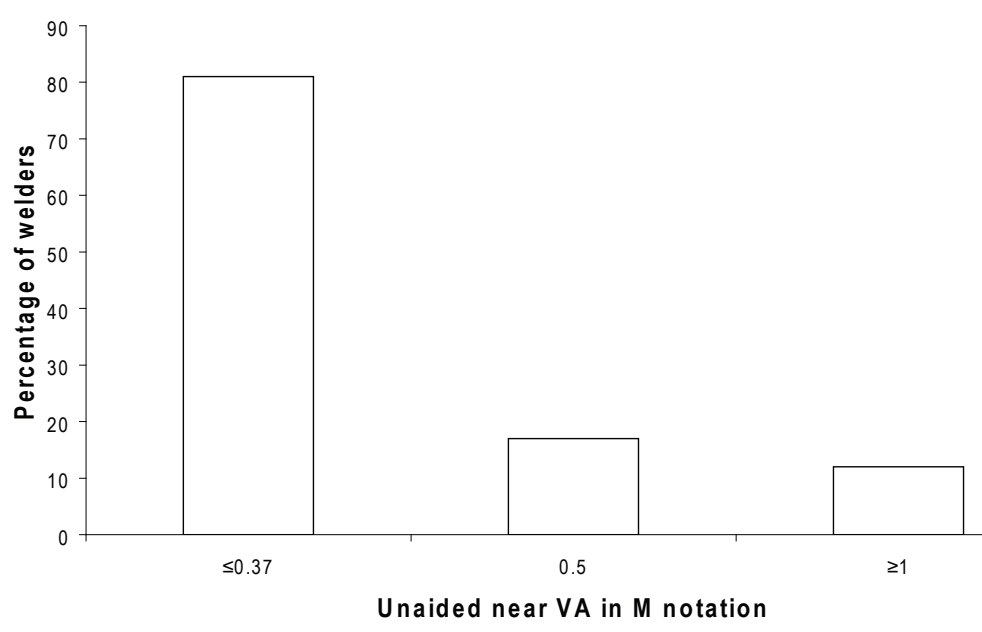

Figure 4: Showing the number of welders who read near VA. The majority $(81 \%)$ could read $\leq 0.37 \mathrm{M}$.

Following pinhole tests, there was an improvement in distance VA in $93 \%$ (65) of the $47 \%$ welders who had poor VA, indicating that they had refractive errors, but there was no improvement in 7\% (5) of the welders, indicating that they probably had pathological conditions. Ophthalmoscopy including external examination revealed that $7 \%$ (10) welders had cup disc ratio $(\mathrm{H} / \mathrm{V})$ greater than $0.6 / 0.5$. Pterygia was seen in $14 \%(21)$ of the welders while $5 \%$ (8) had pinguecula. No abnormality was obvious in the corneas. With the Amsler grid, 94\% (141) of the welders had good macular integrity, but $6 \%$ (9) reported that the lines were blurred or distorted and that the squares were unequal in size (metamorphopsia), suggesting that they had pathological macular conditions.

\section{Discussion}

This study was carried out because it was considered necessary to establish the oculo-visual conditions of the welders in the Capricorn district of the Limpopo Province. The district was chosen due to its proximity to the University of Limpopo where two of the researchers were based. Although tests were carried out in different locations, attempts were made to ensure reasonable environments for each test carried out. All tests were done in places where there was enough space and illumination.

The majority of the welders were aged between 20 and 30 years. This may be because this age group is still in their prime working age; hence it was easy to find employment in the welding industries in the towns. The fact that all the welders were males could be related to the cultural aspect of life among the people of the Province as in other parts of the country. Males often do all the seemingly difficult jobs across the different cultures. This explains why women were not included in the study. However, this does not mean that females may not be engaged in welding at all. It is possible that women engaged in welding in the places we did not visit. The reason all the welders being black may be attributed to the fact that presently in South Africa; many black people have low levels of education ${ }^{25}$. Therefore they can only seek employment from such industries where they mostly need hard work than academic qualifications. It will be of interest to see how this demography changes in the future, because many South Africans have been engaged in education at all levels since independence in 1994. Obviously, this will impact on the demography of industries such as welding in the future.

Although $32 \%$ (48) of the welders reported difficulties seeing distant objects in the case history, after VA measurement, a greater number, 47\% (70), had VA worse than $6 / 6$. This implied that $15 \%$ (22) of the welders had less than optimal vision of which they 
were unaware. Out of the $47 \%$ of the welders with less than 6/6 VA, following pinhole, there was an improvement in VA in 93\% (65) of the welders, hence the poor VA were as a result of refractive errors such as myopia, hyperopia, or astigmatism. Therefore, the poor vision in only $7 \%$ (5) of the $47 \%$ of welders with VA less than 6/6 was due to ocular pathology. However, there are reports ${ }^{26}$ that welding radiations cause lenticular and retinal problems and damages due to welding have also been linked to visual functional defects such as reduced distance and near vision ${ }^{27}$. Also, the abnormal cup/disc ratio found in $7 \%(10)$ and abnormal Amsler grid findings found in 6\% (9) of the welders are possible causes of reduced VA. It could not be established whether these pathologies were welding-related conditions or not.

Although 81\% (121) had no near vision problems, $19 \%$ (29) could not read $0.37 \mathrm{M}$ print and this was attributed to presbyopia as many of these welders were over 40 years. Near vision problems, whether refractive or pathological can negatively impact on welding efficiency and can result in accidents. It is therefore important that welders have their refractive errors corrected for efficient welding. The report of double vision by $43 \%$ (65) of the welders could probably be due to some form of binocular problems. The reported colour vision problems by $11 \%$ (16) of the welders could be due to some pathological affection of the macula or congenital in nature. It is therefore, recommended that welders should have their eyes examined regularly.

The $15 \%$ (22) of the welders who reported eye injuries during welding operations in the previous month suggests a possible deficiency in general eye safety precautions, however, poor vision may also contribute to the incidence of injuries. Therefore, welders should have their eyes examined regularly and be given appropriate optical devices to minimize the risk of eye injuries ${ }^{28}$. Unfortunately, the types of injuries sustained by the welders in this study were not established.

Both pterygia and pingueculae have been associated with UVR which is emitted by welding $\operatorname{arcs}^{1,29}$. The presence of pterygia in 14\% (21) and pinqueculae in $5 \%$ (8) of the welders in this study may be difficult to associate with the welding process alone since sunlight and other noxious stimuli have been associated with their development. The presence of these two conditions could therefore, not be justifiably related to welding as a control group was not examined, also our clinical experience show that the two conditions are common occurrences in the Limpopo province of South Africa. It is therefore, recommended that any future study looking at the effects of welding on conjunctival tissues should include a control group.

\section{Conclusion and recommendations}

The study established that, although many of the welders had normal oculo-visual status, there were a few with ocular disorders such as poor distance and near vision, double vision, pterygia and pingueculae which warrant further assessment and management by eye care professionals. In view of these findings, eye care education and eye protection of welders should form part of the overall work place safety program in the Limpopo Province. This may be organised by the Government and other agencies within the Province. Eye care education aimed at preventing ocular damage by welding processes should include the use of appropriate protection devices and prevention of exposure to radiation when not welding. This will reduce or eliminate the hazards associated with the welding process. A program of this nature will improve safety and reduce ocular symptoms and risk of eye injuries among welders in South Africa.

\section{References}

1. Ten-Kate T, Collins MJ. A survey of symptoms and eye safety practices among welders. Clin Exp Optom 199073 79-85.

2. Howden DG, Desmeules MJA, Saracci, Sprince NL, Herber PI. Respiratory hazards of welding: occupational exposure characterization. Am Rev Res Dis 1998138 1047-1075.

3. Meo SA, Al-Khlaiwi T. Health hazards of welding fumes. Saudi Med J 200324 1176-1182.

4. Antonini JM. Health effects of welding. Critic Rev Toxicol 200333 61-103.

5. Ishioka M, Shimmura S, Tsubota K. Pterygium and dry eye. Doc Ophthalmol 2001215 209-211.

6. Norn M, Frank C. Long-term changes in the outer part of the eye in welders. Acta Ophthalmol Scand 199169 382386.

7. Villaune JE, Wasti K, Liss-Suster D, Hsiao S. Effects of welding on health. American Welding Society, (EDS). 1979.

8. Hendkind M, Friedman P. UV radiation emitted by welding at work stands. Int J Occup Med Environ Health 1976 32 87-92.

9. Bernadino VB, Naidoff MA, Clark WH. Malignant melanoma of the conjunctiva. Am J Ophthalmol 197682 3833294. 
10. Delcourt C, Carriére I, Ponton-Sanchez A, Lacroux A, Covacho M, Papoz L, POLA Study Group. Light Exposure and the Risk of Cortical, Nuclear and Posterior Subcapsular Cataracts. Arch Ophthalmol 2000118 385-392.

11. Kim EA, Kim BG, Yi CH, Kim IG, Chae CH, Kang SK. Macular degeneration in an arc welder. Ind Health 200745 371-373.

12. Oriowo OM, Cullen AP, Chou BR, Sivak JG. Action spectrum and recovery for In Vitro-Induced cataract using whole lenses. IOVS 200142 2597-2601.

13. Gallagher RP, Lee TK. Adverse effects of ultraviolet radiation. A brief review. Progress in Biophysics and Molecular biology 200692 119-131.

14. Holly EA, Aston DA, Ahn DK, Smith AH. Intraocular melanoma linked to occupations and chemical exposures. Epidemiol 19967 55-61.

15. Berkow R. Ophthalmologic disorders. In: The Merck Manual, Berkow R. (ed.), Merck Research Laboratories, Rahway, NJ 1992.

16. McCarty CA, Taylor HR. Recent developments in vision research. Invest Ophthalmol Vis Sci 199637 1720-1723.

17. Ramsy: Part II. Presentation Summaries, The Photodermatoses, Second Symposuim On Ultraviolet Related Diseases, Hotel Vancouver, British Columbia, May 25-26,1996, Chronic Diseases in Canada 1997 1 456-457.

18. Goff T. Flexible welding protection. Occup Health Safety 200675 32-34.

19. Oduntan AO. A survey of eye safety practices among welders in Nigeria. Clin Exp Optom 199881 1-2.

20. Jarnuskieswicz I, Knapnik A, Kwiatkowski B. Particle size distribution of welding fume depending on the microclimate conditions of the welder's working places. Bull Inst Mar Med 196617 73-76.

21. Cullen AP, Oriowo OM, Voisin CA. Anterior eye focusing of peripheral ultraviolet and visible radiation albedo. Clin Exp Optom 199780 80-86.

22. South African Occupational Health and Safety Act, No 181 of 1993. Government Gazette No. 28162, 2005.

23. Chou BR, Cullen AP. Ocular hazards of industrial spot welding. Optom Vis Sci 199673 424-427.

24. The Constitution of the Republic of South Africa. Chapter 2: Bill of Rights, 1996.

25. South African Department of Education. Report of the Ministerial Committee on Rural Education: A new vision for rural schooling. May 2005.

26. Rabley AS, Kenney AH. Welding process and ocular hazards and protection. Am J Ophthalmol 198192 77-84.

27. Gupta MN, Singh H. Ocular Effects and Visual Performance in Welders, Report No. 27, Central Labour Institute, Government of India, 1978.

28. Sithole HL. Eye safety practices, ocular injury prevalence and knowledge of occupational hazards associated with welding among welders in the Capricorn District, Limpopo Province. Master's dissertation in Optometry, University of Limpopo, South Africa 2007.

29. Okuno T, Ojima J, Saito H. Ultraviolet radiation emitted by CO2 arc welding. Ann Occup Hyg 200145 597-601. 